\title{
Exploring the Influence of Supervisor Support, Fit, and Job Attractiveness on Service Employee Job Resourcefulness: An Abstract
}

\author{
Eric G. Harris
}

\begin{abstract}
Service managers strive to ensure both service efficiency and effectiveness, and as such, a growing stream of research has been devoted to the "job resourcefulness" (JR) construct (Harris et al. 2013; Licata et al. 2003). Introduced by Licata and colleagues (2003) as "an enduring disposition to garner scarce resources and overcome obstacles in the pursuit of job-related goals," the construct was developed at a time when calls were made for work on productivity and how services can "do more with less." Today, doing more with less remains a critical part of service success, as when uncertainties in the economy lead to either increased or decreased hiring.

JR has been shown to influence objective sales performance (Harris et al. 2013), supervisor- and self-rated performance (Licata et al. 2003), job satisfaction, and intentions to leave the firm (Harris et al. 2006). Research also indicates that JR is influenced by conscientiousness and openness to experience from the five-factor model (Costa and McCrae 1985) of personality. The extant research stream has focused exclusively on personality variables, leaving researchers and managers alike the question of what contextual factors influence the construct. That is, other than providing personality testing, what can managers do to foster JR in their employees? The current work addresses this issue by exploring the impact of supervisor support, job fit, and job attractiveness on JR while controlling for the influence of conscientiousness and openness to experience.

An online survey tool (Qualtrics) was used for data collection. The setting was the banking industry. Results indicate that both supervisor support and job fit influence JR. Beyond simply hiring employees who have the right personality profiles, managers can encourage resourcefulness not only by ensuring job fit but also by providing adequate levels of supportiveness. It is noted that job attractiveness did not influence JR. This is the first study to consider the impact of three important organizational climate variables-supervisor support, job fit, and job attractiveness on JR. Though preliminary in nature, the results provide evidence that these climate variables impact the JR of service employees.
\end{abstract}

\author{
E. G. Harris (四) \\ Pittsburg State University, Pittsburg, KS, USA \\ e-mail: eharris@pittstate.edu
}

